\title{
Clinical Pharmacokinetics of the Androgen Receptor Inhibitor Darolutamide in Healthy Subjects and Patients with Hepatic or Renal Impairment
}

\author{
Christian Zurth ${ }^{1}$ (D) Pirjo Nykänen ${ }^{2} \cdot$ Gary Wilkinson $^{1} \cdot$ Päivi Taavitsainen $^{3} \cdot$ Annamari Vuorela $^{2} \cdot$ Funan Huang $^{4}$. \\ Susanne Reschke ${ }^{1} \cdot$ Mikko Koskinen $^{2}$
}

Accepted: 27 September 2021 / Published online: 6 December 2021

(c) The Author(s) 2021

\begin{abstract}
Background Darolutamide is a second-generation androgen receptor inhibitor approved for the treatment of nonmetastatic castration-resistant prostate cancer at a dosage of $600 \mathrm{mg}$ orally twice daily.

Objective We aimed to fully characterize the pharmacokinetic profile of darolutamide, its diastereomers, and its main active metabolite, keto-darolutamide.

Methods Single-dose and multiple-dose pharmacokinetics of ${ }^{14} \mathrm{C}$-labeled and non-labeled darolutamide were evaluated in healthy subjects and patients with hepatic or renal impairment.

Results Following darolutamide oral tablet administration, peak plasma concentrations were reached 4-6 h after dosing. Darolutamide elimination was characterized by a half-life of $13 \mathrm{~h}$. Steady state was reached after approximately 2 days of twice-daily dosing. Pharmacokinetics of the diastereomers and keto-darolutamide followed similar trends to the parent compound. Darolutamide absorption from the tablet was lower than from the oral solution; tablet absolute bioavailability was $\sim 30 \%$ in the fasted state but improved to $60-75 \%$ when given with food. The unbound fraction of darolutamide in plasma was $7.8 \%$. The administered 1:1 ratio of the diastereomers $(S, R)$-darolutamide and $(S, S)$-darolutamide changed to $\sim 1: 6$ in plasma following multiple dosing. Similar exposure and diastereomer ratios after single and multiple dosing indicate timeindependent (no autoinduction) linear pharmacokinetics. Darolutamide exposure increased in patients with moderate hepatic or severe renal impairment vs healthy subjects; dose adaptation at treatment initiation should be considered in these patients. Conclusions Darolutamide $600 \mathrm{mg}$ twice daily demonstrates predictable linear pharmacokinetics and sustainably high plasma concentrations, suggesting the potential for constant inhibition of the androgen receptor signaling pathway.
\end{abstract}

Clinical Trials Registration NCT02418650, NCT02894385, NCT02671097.

\section{Introduction}

Darolutamide (Nubeqa ${ }^{\circledR}$, formerly ODM-201) is a novel, potent, and selective non-steroidal second-generation androgen receptor inhibitor developed for the treatment of prostate cancer [1]. Darolutamide is structurally distinct from other

Christian Zurth

christian.zurth@icloud.com

1 Pharmaceuticals, Clinical Pharmacology Oncology, Bayer AG, Muellerstr. 178, 13353 Berlin, Germany

2 Orion Corporation Orion Pharma, Espoo, Finland

3 Orion Corporation Orion Pharma, Turku, Finland

4 Bayer Healthcare Pharmaceuticals, Whippany, NJ, USA androgen receptor inhibitors approved for prostate cancer (enzalutamide and apalutamide). It exists as a 1:1 mixture of two diastereomers, $(S, R)$-darolutamide and $(S, S)$-darolutamide [2]. These diastereomers interconvert via the major metabolite keto-darolutamide (Fig. 1 in the Electronic Supplementary Material [ESM]), and all three compounds have similar pharmacologic activity in vitro [2-6].

Darolutamide $600 \mathrm{mg}$, administered as two 300-mg tablets orally twice daily (BID), demonstrated significantly prolonged overall survival (hazard ratio $0.69 ; 95 \%$ confidence interval $0.53-0.88 ; p=0.003$ ) and metastasis-free survival (40.4 months vs 18.4 months, $p<0.001$ ) compared with placebo and a favorable safety profile in patients with nonmetastatic castration-resistant prostate cancer (CRPC) in the phase III ARAMIS trial (NCT02200614) [7, 8]. Three phase I/II clinical trials (ARADES [NCT01317641], ARAFOR 
Digital Features for this article can be found at https://doi.org/ 10.6084/m9.figshare.16674397.

\section{Key Points}

Darolutamide is an oral androgen receptor inhibitor approved for men with nonmetastatic castration-resistant prostate cancer. Optimal use of darolutamide depends on the understanding of its pharmacokinetics; the present article therefore provides information on the absorption, distribution, and elimination of the compound.

Darolutamide is a mixture of two stereoisomers (diastereomers), which exhibit similar properties and contribute equally and interchangeably to the efficacy and safety of darolutamide.

Following oral administration of darolutamide as a tablet to healthy subjects, it is gradually absorbed, well distributed, and eliminated with a relatively short effective halflife. Sustainable steady-state concentrations are achieved within $\sim 2$ days, indicating that darolutamide will start working quickly and that drug exposure can be easily adjusted if necessary. Darolutamide and its metabolites are processed and eliminated via the liver and kidneys, resulting in recommended dose adjustments in patients with severe renal or moderate hepatic impairment.

[NCT01784757], and Study 17719 [NCT02363855]) demonstrated the safety and antitumor activity of darolutamide in men with metastatic CRPC $[1,9,10]$. These studies included pharmacokinetic analyses, demonstrating gradual absorption and 2-fold to 2.5-fold increased bioavailability when darolutamide was administered with food vs fasted conditions, regardless of meal type (i.e., high fat/calorie or low fat/calorie) $[9,10]$, and that darolutamide exhibited similar pharmacokinetic profiles in Western and Japanese patients with metastatic CRPC [10]. To fully characterize the pharmacokinetic profile of darolutamide and the effects of intrinsic factors, the pharmacokinetic characteristics of the parent compound, its diastereomers, and its active metabolite keto-darolutamide have been evaluated in healthy subjects and in patients without cancer with renal or hepatic impairment.

\section{Methods}

\subsection{Study Populations}

Pharmacokinetic results from three phase I clinical trials are reported (Table 1): a trial in healthy male subjects
(ARIADME, NCT02418650), a trial evaluating the effect of impaired hepatic or renal function in male patients without cancer (Study 17721, NCT02894385), and a drug-drug interaction trial that included single-dose and multiple-dose pharmacokinetic analyses (Study 17723, NCT02671097 [11]). All studies were conducted in accordance with the International Council for Harmonization Good Clinical Practice, the principles of the Declaration of Helsinki, and all applicable national regulations. An independent ethics committee at each study site approved each study protocol, and all participants provided written informed consent.

\subsection{Pharmacokinetic and Analytical Methods}

Pharmacokinetic blood samples were collected according to schedules defined for each trial, using $\mathrm{K}_{2}$-EDTA as the anticoagulant. The bioanalytical methods used for pharmacokinetic sampling are summarized in the ESM.

The plasma concentrations of darolutamide (sum of concentrations of $(S, R)$-darolutamide and $(S, S)$-darolutamide) and keto-darolutamide were used to calculate pharmacokinetic parameters in non-compartmental analyses using WinNonlin version 5.3 (Pharsight Corporation, Mountain View, CA, USA) and applicable complementary software. The following pharmacokinetic parameters were estimated: maximum observed plasma concentration $\left(C_{\max }\right)$; time to $C_{\max }\left(t_{\max }\right)$; area under the concentration-time curve (AUC) from time 0 to the time of the last measurable concentration $\left(\mathrm{AUC}_{0-\text { tlast }}\right.$ ), to infinity (AUC 0 -inf), and to 12 or $48 \mathrm{~h}$ after darolutamide administration $\left(\mathrm{AUC}_{0-12}\right.$ and $\mathrm{AUC}_{0-48}$, respectively); terminal halflife $\left(t_{1 / 2}\right)$ and effective $t_{1 / 2}$; clearance following intravenous (IV) administration; and volume of distribution. Diastereomer ratios in plasma based on $\mathrm{AUC}_{0-\text { inf }}$ and ketodarolutamide:darolutamide ratios based on $\mathrm{AUC}_{0-\mathrm{inf}}$ were calculated after oral and IV administration. Accumulation ratios based on $\mathrm{AUC}_{0-12}$ and $C_{\max }$ for single vs multiple dosing were calculated for darolutamide, both diastereomers, and keto-darolutamide. The linearity factor $\left(R_{\mathrm{LIN}}\right.$; the ratio of multiple-dose $\mathrm{AUC}_{0-12}$ to single-dose $\mathrm{AUC}_{0-\text { inf }}$ ) was also calculated. Effective $t_{1 / 2}$ was based on the mean accumulation ratio of $\mathrm{AUC}_{0-12}$ at steady state divided by $\mathrm{AUC}_{0-12}$ after single administration.

Protein binding of darolutamide, $(S, R)$-darolutamide, $(S, S)$-darolutamide, and keto-darolutamide, and blood partitioning of darolutamide and keto-darolutamide were investigated in vitro using blood and plasma from healthy male subjects and patients without cancer with moderate hepatic impairment or severe renal impairment. Unbound fractions were determined by equilibrium dialysis (see ESM). 
Table 1 Overview of darolutamide clinical studies with pharmacokinetic evaluations in healthy subjects and in patients without cancer with severe renal or moderate hepatic impairment

\begin{tabular}{|c|c|c|c|c|}
\hline \multirow[t]{2}{*}{ Study } & \multirow[t]{2}{*}{ Dose } & \multirow[t]{2}{*}{ Subjects $^{\mathrm{a}}$} & \multicolumn{2}{|c|}{$\begin{array}{l}\text { Baseline characteristics } \\
\text { (pharmacokinetic populations) }\end{array}$} \\
\hline & & & $\begin{array}{l}\text { Age in years, mean } \\
\text { (SD) [range] }\end{array}$ & $\begin{array}{l}\mathrm{BMI} \text { in } \mathrm{kg} / \\
\mathrm{m}^{2} \text {, mean } \\
(\mathrm{SD})\end{array}$ \\
\hline PK/bioavailability (ARIADME) & $\begin{array}{l}\text { Part } 1: 1 \times 300 \mathrm{mg} \text { oral, fasted (tab- } \\
\text { let) }+1 \times 100 \mu \mathrm{IV} \text { (V) }\left({ }^{14} \mathrm{C}-\text { labeled) }\right. \\
\text { Part } 2: 1 \times 300 \mathrm{mg} \text { oral } \\
\left({ }^{14} \mathrm{C}-\text {-labeled }\right), \text { fasted (solution) }\end{array}$ & $\begin{array}{l}12 \text { healthy male individuals ( } 6 \text { in } \\
\text { Part } 1 \text { and } 6 \text { in Part 2) }\end{array}$ & $55.5(5.54)[50-65]$ & $28.0(2.86)$ \\
\hline $\begin{array}{l}\text { Single-dose and multiple-dose } \\
\mathrm{PK}^{\mathrm{b}} \text { (Study 17723) }\end{array}$ & $\begin{array}{l}\text { Day 1: } 1 \times 600 \mathrm{mg} \text { oral, fed (tablet) } \\
\text { Days 4-7: } 600 \mathrm{mg} \text { BID oral, fed } \\
\text { (tablet) }\end{array}$ & 15 healthy male individuals & $52.5(3.4)[47-58]$ & $24.8(2.0)$ \\
\hline \multirow{4}{*}{$\begin{array}{l}\text { Renal and hepatic impairment } \\
\text { (Study 17721) }\end{array}$} & \multirow[t]{4}{*}{$1 \times 600 \mathrm{mg}$ oral, fed (tablet) } & 29 male individuals: & $64.4(8.1)[52-78]$ & $28.8(3.46)$ \\
\hline & & 10 healthy subjects & $61.5(6.5)[55-73]$ & $29.3(2.77)$ \\
\hline & & $\begin{array}{l}9 \text { patients without cancer with } \\
\text { moderate hepatic impairment } \\
\text { (Child-Pugh B) }\end{array}$ & $64.3(8.8)[52-78]$ & $28.4(4.29)$ \\
\hline & & $\begin{array}{l}10 \text { patients without cancer with } \\
\text { severe renal impairment }{ }^{\mathrm{c}}\end{array}$ & $67.3(8.6)[53-76]$ & $28.7(3.58)$ \\
\hline
\end{tabular}

$B I D$ twice daily, $B M I$ body mass index, $e G F R$ estimated glomerular filtration rate, $I V$ intravenous, $P K$ pharmacokinetics, $S D$ standard deviation ${ }^{a}$ All subjects were Caucasian with the exception of one Black subject in Part 2 of the PK/bioavailability study (ARIADME)

${ }^{\mathrm{b}}$ This study also investigated the potential for drug-drug interactions between darolutamide and rosuvastatin (reported elsewhere [11])

${ }^{c}$ Patients with severe renal impairment had eGFR of $15-29 \mathrm{~mL} / \mathrm{min} / 1.73 \mathrm{~m}^{2}$ (estimated according to the four-variable abbreviated 'Modification of Diet in Renal Disease' Study equation), were not undergoing dialysis, and were not expected to start dialysis within 3 months

\subsection{Study Designs}

\subsubsection{Pharmacokinetics and Bioavailability Study}

The ARIADME study was a phase I, single-center, openlabel, non-randomized, two-part trial to determine the absolute bioavailability and pharmacokinetics of darolutamide, its diastereomers, and keto-darolutamide, as well as evaluations of mass balance, metabolism, and excretion routes of darolutamide, which are reported elsewhere [6]. In Part 1 , six healthy male subjects received a single oral dose of darolutamide $300 \mathrm{mg}$ as a tablet, followed by a single IV microtracer dose administered as a 15-min infusion ending at the expected $t_{\max }$ for the oral tablet ( $3 \mathrm{~h}$ post-dose) to assess absolute bioavailability. The microtracer dose did not exceed $100 \mu \mathrm{g}$ of ${ }^{14} \mathrm{C}$-darolutamide and contained $\leq 37 \mathrm{kBq}$ $(1000 \mathrm{nCi}){ }^{14} \mathrm{C}$. In Part 2 , six healthy male subjects received a single oral dose of ${ }^{14} \mathrm{C}$-darolutamide $300 \mathrm{mg}$ as an aqueous propylene glycol solution containing $\leq 6.3 \mathrm{MBq}(171 \mu \mathrm{Ci})$ ${ }^{14} \mathrm{C}$. All doses were administered after overnight fasting.

Pharmacokinetic samples were collected from all subjects receiving darolutamide oral tablets in Part 1 as follows: blood samples were obtained pre-dose and at $0.5,1,1.5,2$, $3,4,5,6,8,12,16,24,48$, and $72 \mathrm{~h}$ post-dose; urine samples were collected from 0 to $12 \mathrm{~h}$ and 12 to $24 \mathrm{~h}$ post-dose, and then at intervals of $24 \mathrm{~h}$ up to $72 \mathrm{~h}$ post-dose. Plasma samples for the IV microtracer dose of ${ }^{14} \mathrm{C}$-darolutamide in Part 1 were collected at the start of the infusion, $10 \mathrm{~min}$ after the start of the infusion, and at the end of the infusion, then at 10, 20, and 40 min post-infusion and at 1, 1.5, 2, 3, 4, 5, $7,9,15,21,45$, and $69 \mathrm{~h}$ post-infusion. Plasma samples for subjects receiving darolutamide oral solution in Part 2 were collected pre-dose, at $0.25,0.5,1,1.5,2,3,4,5,6,8,12,16$, and $24 \mathrm{~h}$ post-dose, then at 24-h intervals up to $168 \mathrm{~h}$ postdose. Urine samples were collected from 0 to $12 \mathrm{~h}$ and 12 to $24 \mathrm{~h}$ post-dose, then at intervals of $24 \mathrm{~h}$ up to $72 \mathrm{~h}$ (tablet) or $168 \mathrm{~h}$ (solution) post-dose. Whole blood samples for total radioactivity after oral solution dosing were collected predose and at $0.5,1,1.5,3,8$, and $24 \mathrm{~h}$ post-dose.

After oral dosing with the solution or tablet, plasma concentrations of darolutamide, its diastereomers, and ketodarolutamide and urine concentrations of the diastereomers were determined in samples using high-performance liquid chromatography mass spectrometry methods that were validated in accordance with regulatory guidance (plasma) $[12,13]$ or were qualified against validated methods (urine). Plasma concentrations of IV ${ }^{14} \mathrm{C}$-labeled darolutamide, $(S, R)$-darolutamide, $(S, S)$-darolutamide, and keto-darolutamide were determined using a validated method consisting of liquid chromatography followed by fractionation and accelerator mass spectrometry. Plasma and whole blood concentrations of ${ }^{14} \mathrm{C}$-radioactivity were determined using 
liquid scintillation counting. Details of the bioanalytical methods are included in the ESM.

\subsubsection{Single-Dose and Multiple-Dose Pharmacokinetics}

The phase I study that included investigation of single-dose and multiple-dose pharmacokinetics of darolutamide was a prospective, open-label, non-randomized, fixed-sequence trial in healthy male subjects, with the primary objective of assessing drug-drug interactions between darolutamide and rosuvastatin [11] (Table 1). Darolutamide $600 \mathrm{mg}$ was administered orally as two $300-\mathrm{mg}$ tablets $30 \mathrm{~min}$ after the start of a standardized meal on day 1 (morning), then BID on days 4-7. Pharmacokinetic blood samples were collected pre-dose and at $0.5,1,1.5,2,2.5,3,4,6,8,12,24,36,38$, 60 , and $72 \mathrm{~h}$ post-dose (for single-dose pharmacokinetics), in the morning on days 4-6 (trough concentration), and predose and at $0.5,1,1.5,2,2.5,3,4,6,8$, and $12 \mathrm{~h}$ post-dose on day 7 (for multiple-dose pharmacokinetics). Plasma samples were extracted using a solid-phase extraction procedure, and concentrations of darolutamide, its diastereomers, and keto-darolutamide were determined using a validated liquid chromatography-tandem mass spectrometry detection assay (see ESM).

\subsubsection{Hepatic and Renal Impairment Study}

An open-label, non-randomized, parallel-group, multicenter, phase I clinical trial was conducted to evaluate the potential effects of hepatic or renal impairment on the pharmacokinetics of darolutamide, its diastereomers, and keto-darolutamide. The study population comprised male patients (aged 45-79 years) who had moderate hepatic impairment or severe renal impairment and an age-matched and weight-matched control group of healthy male subjects. Patients with moderate hepatic impairment were eligible if they had histopathologically confirmed liver cirrhosis and Child-Pugh classification B [14]. Patients with renal impairment were eligible if they had an estimated glomerular filtration rate of $15-29 \mathrm{~mL} / \mathrm{min} / 1.73 \mathrm{~m}^{2}$ according to the fourvariable abbreviated 'Modification of Diet in Renal Disease' Study equation, were not undergoing dialysis or expected to start dialysis in the next 3 months, and had stable renal disease (serum creatinine within $\pm 25 \%$ of the last determination obtained $\leq 3$ months before study entry).

Darolutamide $600 \mathrm{mg}$ was administered orally as two 300-mg tablets 30 min after the start of a standardized breakfast. Pharmacokinetic blood samples were collected pre-dose and at $0.5,1,1.5,2,2.5,3,4,6,8,12,24,36$, and $48 \mathrm{~h}$ postdose. Quantitative analysis of darolutamide, its diastereomers, and keto-darolutamide was performed using a validated liquid chromatography-tandem mass spectrometry detection assay (see ESM). Pharmacokinetic parameters were calculated based on total and unbound concentration-time data for darolutamide, its diastereomers, and keto-darolutamide in plasma.

\section{Results}

\subsection{Participants}

Baseline characteristics of subjects in the three trials are summarized in Table 1.

\subsection{Absolute and Relative Bioavailability}

Darolutamide was gradually absorbed after administration of a single $300-\mathrm{mg}$ oral tablet to healthy subjects in the fasted state. Maximum observed plasma concentration was reached $3.5 \mathrm{~h}$ (range 2.0-4.1 h) post-dose (Table 2). Thereafter, plasma concentrations declined in a biphasic manner, with a terminal $t_{1 / 2}$ of $15.3 \mathrm{~h}$.

When ${ }^{14} \mathrm{C}$-darolutamide $100 \mu \mathrm{g}$ was administered as a single IV microtracer infusion over $15 \mathrm{~min}, C_{\max }$ was reached in plasma at the end of infusion and declined biphasically, with a terminal $t_{1 / 2}$ of $11.8 \mathrm{~h}$ (Table 2; Fig. 2 in the ESM). The elimination of darolutamide from plasma after administration as an oral solution was biphasic, with a terminal $t_{1 / 2}$ of $10.6 \mathrm{~h}$ (Table 2). After a single dose of ${ }^{14} \mathrm{C}$-darolutamide $300 \mathrm{mg}$ as an oral solution, $t_{\max }$ occurred earlier, and the mean $C_{\max }$ and $\mathrm{AUC}_{0 \text {-inf }}$ were 4.8 -fold and 3.5-fold higher, respectively, than the tablet formulation (Table 2).

Determination of bioavailability for the 300-mg oral tablet used the IV microtracer dose as a reference; administration was timed to ensure that pharmacokinetic profiles were matched with regard to $t_{\text {max }}$. For darolutamide administered as a single $300-\mathrm{mg}$ oral tablet to healthy subjects in the fasted state, the absolute bioavailability based on AUC 0 -inf was $29.9 \%$. The absolute bioavailability of darolutamide from the oral solution was estimated to be $98.9 \%$, indicating complete absorption of the dose, which was confirmed by total ${ }^{14} \mathrm{C}$-radioactivity results in plasma and urine (Table 2 in the ESM; the fraction absorbed was $109 \%$ based on plasma AUC of total ${ }^{14} \mathrm{C}$-radioactivity and $127 \%$ based on the amount of total ${ }^{14} \mathrm{C}$-radioactivity excreted in urine).

\subsection{Diastereomer Interconversion}

The darolutamide diastereomers interconvert via the metabolite keto-darolutamide (Fig. 1 in the ESM). The 1:1 diastereomer ratio of $(S, R)$-darolutamide to $(S, S)$-darolutamide in administered darolutamide changed rapidly in plasma, preferring $(S, S)$-darolutamide with all formulations (as shown for IV dosing in Fig. 1). Exposure of $(S, S)$-darolutamide was greater than $(S, R)$-darolutamide, with a shorter mean 
Table 2 Pharmacokinetic parameters following a single 300-mg oral tablet dose of darolutamide, a single IV infusion of ${ }^{14} \mathrm{C}$-darolutamide $100 \mu \mathrm{g}$ over $15 \mathrm{~min}$, and a single oral solution dose of ${ }^{14} \mathrm{C}$-darolutamide $300 \mathrm{mg}$

\begin{tabular}{|c|c|c|c|}
\hline Parameter & $\begin{array}{l}\text { Darolutamide } 300 \mathrm{mg} \text { as } \\
\text { oral tablet }(n=6)\end{array}$ & $\begin{array}{l}\text { Darolutamide } \\
300 \mathrm{mg} \text { as oral } \\
{ }^{14} \mathrm{C} \text {-solution }(n=6)\end{array}$ & $\begin{array}{l}\text { Darolutamide } 100 \mu \mathrm{g} \text { as IV } \\
{ }^{14} \mathrm{C} \text {-microtracer dose }(n=6)\end{array}$ \\
\hline$C_{\max }, \mathrm{ng} / \mathrm{mL}$ & $800(25.0)$ & $3824(19.0)$ & $4127(27.4)^{\mathrm{a}}$ \\
\hline$t_{\max }, \mathrm{h}$ & $3.50(2.00-4.10)$ & $1.58(1.02-3.00)$ & $0.25(0.25-0.25)$ \\
\hline $\mathrm{AUC}_{0-\text { tlast }}, \mathrm{ng} \cdot \mathrm{h} / \mathrm{mL}$ & $12,417(35.6)$ & $45,323(21.2)$ & $12,659(38.2)^{\mathrm{a}}$ \\
\hline $\mathrm{AUC}_{0-\mathrm{inf}}, \mathrm{ng} \cdot \mathrm{h} / \mathrm{mL}$ & $12,898(36.2)$ & $45,573(21.3)$ & $13,645(39.5)^{\mathrm{a}}$ \\
\hline$t_{1 / 2}, \mathrm{~h}$ & $15.3(29.3)$ & $10.6(22.6)$ & $11.8(31.1)$ \\
\hline $\mathrm{CL} / F, \mathrm{~mL} / \mathrm{min}$ & $388(36.2)$ & $110(21.3)$ & $\mathrm{NC}$ \\
\hline $\mathrm{CL}, \mathrm{mL} / \mathrm{min}^{\mathrm{b}}$ & $\mathrm{NC}$ & $\mathrm{NC}$ & $116(39.7)$ \\
\hline $\mathrm{CL}_{\mathrm{R}}, \mathrm{mL} / \mathrm{min}$ & $6.52(10.2)$ & $7.73(20.5)$ & $\mathrm{NC}$ \\
\hline$V_{\mathrm{d}}, \mathrm{mL}$ & $\mathrm{NC}$ & $\mathrm{NC}$ & $118,930(28.9)$ \\
\hline$V_{\mathrm{d}} / F, \mathrm{~mL}$ & $513,569(38.1)$ & $100,863(39.2)$ & $\mathrm{NC}$ \\
\hline$F$ & 0.299 (19.4) & $0.989(21.3)$ & $\mathrm{NC}$ \\
\hline
\end{tabular}

Data are expressed as geometric mean (CV\%), except $t_{\max }$, which is expressed as median (range)

${ }^{14} \mathrm{C}$ radioactive isotope of carbon, $A U C$ area under the plasma concentration-time curve, $A U C_{0-t l a s t}$ AUC from time 0 to the time of the last concentration above the lower limit of quantification, $C L(/ F)$ (apparent) volume of plasma cleared of analyte per unit of time, $C L_{R}$ renal clearance, $C_{\max }$ maximum (peak) plasma concentration, $C V \%$ coefficient of variation, $F$ absolute oral bioavailability, $I V$ intravenous, $N C$ not calculated, $t_{1 / 2}$ elimination half-life, $t_{\max }$ time to peak concentration, $V_{d}(/ F)$ (apparent) volume of distribution of analyte

${ }^{\mathrm{a}}$ For the IV microtracer dose, units were $\mathrm{pg}$ eq $/ \mathrm{mL}$ for $C_{\max }$ and $\mathrm{AUC}_{0-\text { tlast }}$ and $\mathrm{h} \cdot \mathrm{pg} \mathrm{eq} / \mathrm{mL}$ for AUC

${ }^{\mathrm{b}} \mathrm{CL}$ for the IV microtracer dose, $\mathrm{CL} / F$ for the oral tablet and solution terminal $t_{1 / 2}(3.98$ vs $14.2 \mathrm{~h}$ ) and 2.9-fold higher clearance for $(S, R)$-darolutamide vs $(S, S)$-darolutamide after the IV dose, indicating that $(S, R)$-darolutamide was eliminated more rapidly (Table 3 in the ESM). A similar relationship between the diastereomers and the metabolite was observed with oral dosing. After a darolutamide 600-mg oral tablet, the plasma concentration-time profiles for $(S, S)$-darolutamide and keto-darolutamide ran in parallel with that of darolutamide, whereas $C_{\max }$ was reached earlier and declined faster with $(S, R)$-darolutamide (Fig. 2). In later stages, the elimination rate of $(S, R)$-darolutamide approached that of $(S, S)$-darolutamide and keto-darolutamide due to back-formation from keto-darolutamide. This indicates that a reduction in ketodarolutamide back to the parent drug resulted in the formation of both diastereomers, although $(S, S)$-darolutamide formation was favored.

Plasma exposure to keto-darolutamide was greater than darolutamide following dosing with all formulations: the metabolite:parent total concentration ratios, based on $\mathrm{AUC}_{0-\text { inf }}$, were 1.50, 1.67, and 2.06 after the IV microtracer,
Fig. 1 Mean (standard deviation) plasma keto-darolutamide/ darolutamide, $(S, R)$-darolutamide/darolutamide, and $(S, S)$ darolutamide/darolutamide concentration ratio vs time profiles following a single intravenous (IV) dose of ${ }^{14} \mathrm{C}$-darolutamide $100 \mu \mathrm{g}(n=6$ healthy male subjects). $h$ hours

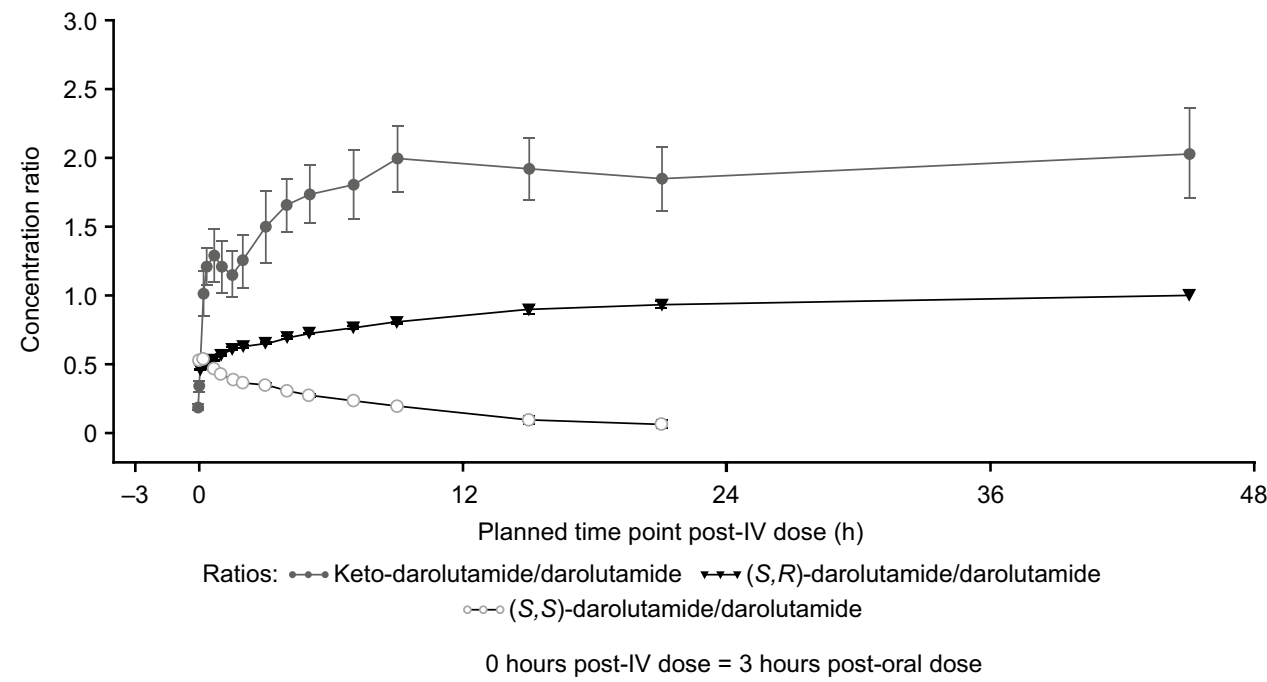


oral tablet, and oral solution doses, respectively. Plasma concentrations of keto-darolutamide declined biphasically, with terminal $t_{1 / 2}$ values similar to darolutamide after the respective IV and oral dosing (Fig. 2, Table 2, Table 3 in the ESM). After oral tablet administration of darolutamide $600 \mathrm{mg}$, plasma concentrations of keto-darolutamide were measurable at the same early timepoints as both diastereomers or the parent compound (Fig. 2), indicating that formation of the metabolite was rapid.

\subsection{Distribution}

In vitro studies in human plasma showed darolutamide binding to plasma proteins with a mean free (unbound) fraction of $\sim 8 \%$ and a lower free fraction for keto-darolutamide $(0.2 \%)$; serum albumin appeared to be the main binding protein for both darolutamide and keto-darolutamide (data on file). These data are consistent with the protein binding analysis of ex vivo samples collected after a single oral administration of darolutamide $600 \mathrm{mg}$, in which the mean free (unbound) fraction in plasma was $7.8 \%$ for darolutamide and $0.12 \%$ for keto-darolutamide. The mean whole blood:plasma ratio of total ${ }^{14} \mathrm{C}$-radioactivity following a single oral solution dose of darolutamide was 0.7 , indicating minor partitioning into blood cells.

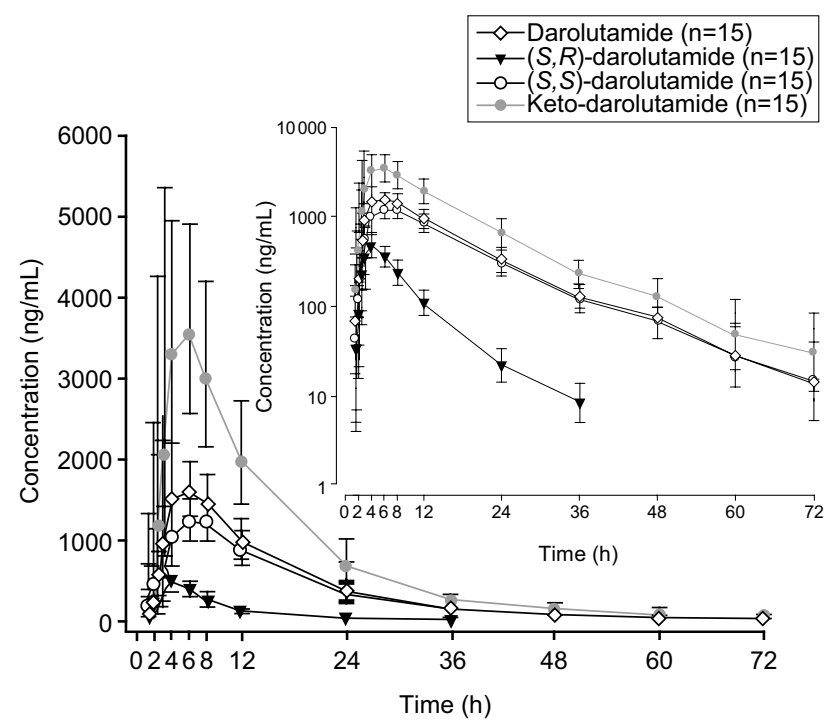

Fig. 2 Geometric mean (standard deviation) concentration of darolutamide, $(S, R)$-darolutamide, $(S, S)$-darolutamide, and keto-darolutamide following a single dose of darolutamide $600 \mathrm{mg}$ as two $300-\mathrm{mg}$ oral tablets in healthy male subjects: linear and semilogarithmic plots $(n=15) . h$ hours

\subsection{Single-Dose and Multiple-Dose Pharmacokinetics}

Following administration of a single oral dose of darolutamide $600 \mathrm{mg}$ with food to healthy male subjects, plasma darolutamide concentrations increased gradually (Fig. 3). The mean peak plasma concentration of $1.77 \mu \mathrm{g} / \mathrm{mL}$ was reached $\sim 6 \mathrm{~h}$ post-dose (Table 3 ). Plasma concentrations then declined, with a mean terminal $t_{1 / 2}$ of $11.6 \mathrm{~h}$; mean overall exposure as calculated by $\mathrm{AUC}_{0-\text { inf }}$ was $26.2 \mu \mathrm{g} \cdot \mathrm{h} / \mathrm{mL}$. Following multiple doses with darolutamide $600 \mathrm{mg}$ BID for 4 days, median $\mathrm{t}_{\max }$ was reduced to approximately $4 \mathrm{~h}$, and exposure doubled, with accumulation ratios based on AUC ${ }_{0-12}$ and $C_{\max }$ of 2.1 and 1.9, respectively (Fig. 3, Table 3). The mean multiple-dose $\mathrm{AUC}_{0-12}$ was $28.8 \mu \mathrm{g} \cdot \mathrm{h} / \mathrm{mL}$, similar to single-dose $\mathrm{AUC}_{0-\text { inf }}$, indicating that the pharmacokinetics of darolutamide are linear with time $\left(R_{\mathrm{LIN}}\right.$ of 1.1). The estimated effective $t_{1 / 2}$, based on the $\mathrm{AUC}_{0-12}$ accumulation ratio and calculated using the method of Sahin and Benet 2008 [15], was $13.0 \mathrm{~h}$.

After single and repeated administration of darolutamide $600 \mathrm{mg}$ as oral tablets, the ratios of $(S, R)$-darolutamide to $(S, S)$-darolutamide were approximately $1: 5$ and 1:6 in plasma, respectively, with maximum concentrations of keto-darolutamide and both diastereomers observed at similar post-dose timepoints to darolutamide. Mean terminal $t_{1 / 2}$ values for the four analytes ranged from 11.6 to $14.5 \mathrm{~h}$ (Table 3$)$. Despite a faster elimination of $(S, R)$-darolutamide following $C_{\max }$, a longer terminal $t_{1 / 2}$ was observed as a result of back-formation from keto-darolutamide over time (Fig. 2). Consequently, the linear phase for $(S, R)$-darolutamide on the semi-logarithmic scale at later timepoints resulted in

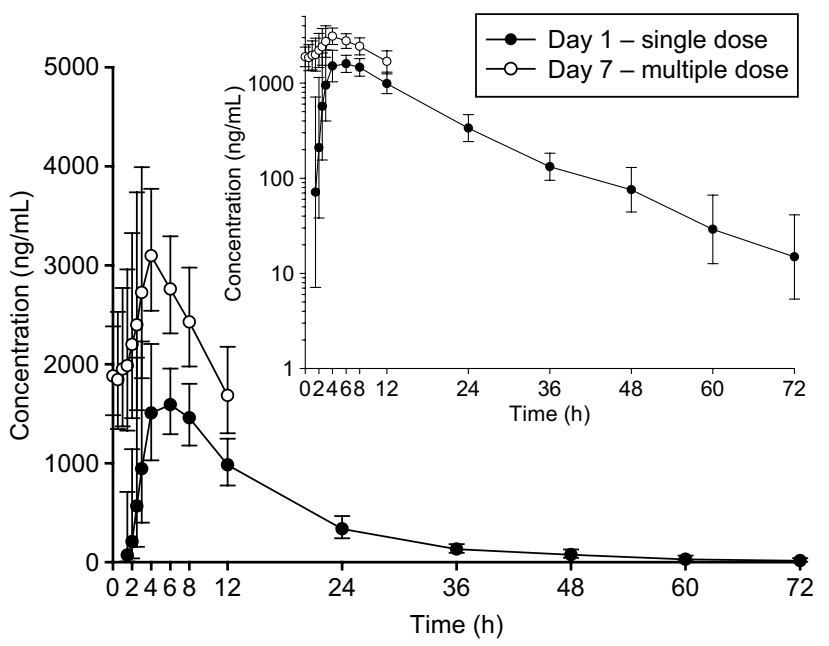

Fig. 3 Mean plasma concentration-time profile of darolutamide 600 mg following single and multiple twice-daily oral administration in healthy male subjects: linear and semilogarithmic plots $(n=15)$. $h$ hours 
Table 3 Plasma pharmacokinetic parameters of darolutamide, $(S, R)$-darolutamide, $(S, S)$-darolutamide, and keto-darolutamide taken with food in healthy subjects receiving single (day 1 ) and multiple (day 7) oral doses of $600 \mathrm{mg}$ BID

\begin{tabular}{|c|c|c|c|c|c|}
\hline & \multirow[t]{2}{*}{ Parameter } & \multicolumn{4}{|c|}{ Geometric mean/geometric CV\% (range) } \\
\hline & & Darolutamide $(n=15)$ & $\begin{array}{l}(S, R) \text {-darolutamide } \\
(n=15)\end{array}$ & $\begin{array}{l}(S, S) \text {-darolutamide } \\
(n=15)\end{array}$ & $\begin{array}{l}\text { Keto-darolutamide } \\
(n=15)\end{array}$ \\
\hline \multirow[t]{6}{*}{ Day 1 (single dose) } & $C_{\max }, \mathrm{ng} / \mathrm{mL}$ & $1.77 / 26.4(1.14-3.05)$ & $553 / 33.5(340-1010)$ & $1.33 / 22.4(0.910-2.04)$ & $3.96 / 32.4(2.51-8.66)$ \\
\hline & $t_{\max }, \mathrm{h}^{\mathrm{a}}$ & $5.97(2.50-7.95)$ & $3.97(1.02-6.02)$ & $5.98(2.50-8.00)$ & $4.00(2.50-6.02)$ \\
\hline & $\mathrm{AUC}_{0-12}, \mu \mathrm{g} \cdot \mathrm{h} / \mathrm{mL}$ & $13.6 / 25.7(8.90-21.1)$ & $3.15 / 29.1(1.85-5.42)$ & $10.4 / 25.4(6.60-15.6)$ & $29.3 / 29.9(19.0-58.2)$ \\
\hline & $\mathrm{AUC}_{0-\mathrm{inf}}, \mu \mathrm{g} \cdot \mathrm{h} / \mathrm{mL}$ & $26.2 / 22.4(16.7-36.0)$ & $4.26 / 25.9(2.53-6.93)$ & $22.1 / 22.5(13.6-29.4)$ & $53.9 / 28.5(32.6-91.3)$ \\
\hline & $\mathrm{AUC}_{0-\text { tlast }}, \mu \mathrm{g} \cdot \mathrm{h} / \mathrm{mL}$ & $25.8 / 22.1(16.5-35.0)$ & $4.11 / 26.2(2.46-6.63)$ & $21.6 / 22.0(13.4-28.9)$ & $52.8 / 28.4(32.4-88.7)$ \\
\hline & Terminal $t_{1 / 2}, \mathrm{~h}$ & $11.6 / 32.7(6.63-18.9)$ & $14.5 / 70.0(4.03-31.3)$ & $12.4 / 37.0(6.63-20.8)$ & $12.9 / 54.4(5.69-34.6)$ \\
\hline \multirow{7}{*}{$\begin{array}{l}\text { Day } 7 \text { (multiple } \\
\text { doses) }\end{array}$} & $C_{\max }, \mathrm{ng} / \mathrm{mL}$ & $3.33 / 20.8(2.28-4.31)$ & $684 / 31.5(417-1050)$ & $2.71 / 18.8(1.93-3.58)$ & $7.98 / 33.4(3.66-12.3)$ \\
\hline & $t_{\max }, \mathrm{h}^{\mathrm{a}}$ & $3.98(2.00-5.98)$ & $3.00(0.967-4.00)$ & $3.98(0.00-6.02)$ & $3.00(1.48-5.97)$ \\
\hline & $\mathrm{AUC}_{0-12}, \mu \mathrm{g} \cdot \mathrm{h} / \mathrm{mL}$ & $28.8 / 22.1(20.2-37.1)$ & $3.91 / 30.1(2.07-5.85)$ & 24.8/21.7 (17.6-31.8) & $65.9 / 33.6(29.1-110)$ \\
\hline & Effective $t_{1 / 2}^{\mathrm{b}}$ & 13.0 & 5.08 & 15.3 & 14.1 \\
\hline & $\mathrm{R}_{\mathrm{A}} \mathrm{AUC}$ & 2.1 & 1.2 & 2.3 & 2.2 \\
\hline & $\mathrm{R}_{\mathrm{A}} \mathrm{C}_{\max }$ & 1.9 & 1.2 & 2.0 & 2.0 \\
\hline & $\mathrm{R}_{\mathrm{LIN}}$ & 1.1 & 0.9 & 1.1 & 1.2 \\
\hline
\end{tabular}

$A U C$ area under the concentration-time curve, $A U C_{0-12}$ AUC from time 0 to $12 \mathrm{~h}$ after administration, $A U C_{0-t l a s t}$ AUC from time 0 to the time of the last concentration above the lower limit of quantification, $B I D$ twice daily, $C_{\max }$ maximum (peak) plasma concentration, $C V \%$ coefficient of variation, $R_{A} A U C$ accumulation ratio based on $\mathrm{AUC}_{0-12}, R_{A} C_{\max }$ accumulation ratio based on $\mathrm{C}_{\max }, R_{L I N}$ linearity factor (ratio of multiple-dose $\mathrm{AUC}_{0-12}$ to single-dose AUC), $t_{1 / 2}$ elimination half-life, $t_{\max }$ time to peak concentration

${ }^{\mathrm{a}}$ Median (range)

${ }^{\mathrm{b}}$ Estimated effective half-life based on $\mathrm{AUC}_{0-12}$ accumulation ratio and calculated according to the method of Sahin and Benet 2008 [15]

an apparently longer terminal $t_{1 / 2}$. The effective $t_{1 / 2}$ ranged from 13.0 to $15.3 \mathrm{~h}$ for darolutamide, $(S, S)$-darolutamide, and keto-darolutamide, which is similar to the terminal $t_{1 / 2}$ of these compounds. However, the effective $\mathrm{t}_{1 / 2}$ of $(S, R)$ darolutamide of $5.08 \mathrm{~h}$ was much shorter than the terminal $t_{1 / 2}$ of $14.5 \mathrm{~h}$. The effective $t_{1 / 2}$ may therefore better reflect the faster elimination of $(S, R)$-darolutamide observed early after dosing rather than the longer terminal $t_{1 / 2}$, which reflects only a small proportion of the elimination of this diastereomer.

After single and multiple dosing of darolutamide, plasma exposure of keto-darolutamide was approximately twofold higher than that of darolutamide. Plasma exposure for ketodarolutamide, $(S, R)$-darolutamide, and $(S, S)$-darolutamide was similar after single administration $\left(\mathrm{AUC}_{0-\text { inf }}\right)$ and multiple administration $\left(\mathrm{AUC}_{0-12}\right.$ on day 7$)$, indicating that the metabolite pharmacokinetics was time independent and predictable (Table 3). Trough concentrations of darolutamide, both diastereomers, and keto-darolutamide reached steadystate levels after only 1 day of BID treatment.

\subsection{Effects of Hepatic and Renal Impairment on the Pharmacokinetics of Darolutamide}

A single dose of darolutamide $600 \mathrm{mg}$ administered with food was gradually absorbed, with a median $t_{\max }$ of $4 \mathrm{~h}$ in healthy subjects and those with moderate hepatic impairment or severe renal impairment (Table 4). In patients with moderate hepatic impairment (Child-Pugh class B), darolutamide $C_{\max }$ increased 1.5 -fold and exposure $\left(\mathrm{AUC}_{0-48}\right)$ increased 1.9-fold compared with values seen in healthy subjects (Fig. 3 in the ESM). Patients with severe renal impairment had a 1.6-fold higher $C_{\max }$, a 2.5 -fold greater exposure $\left(\mathrm{AUC}_{0-48}\right)$, and a prolonged terminal $\mathrm{t}_{1 / 2}$ for darolutamide vs healthy subjects (Table 4, Fig. 3 in the ESM). The terminal $t_{1 / 2}$ in patients with moderate hepatic impairment did not change compared with healthy subjects (Table 4). Plasma exposure $\left(\mathrm{AUC}_{0-48}\right)$ of keto-darolutamide was increased in patients with renal or hepatic impairment, but the increase was less pronounced than for darolutamide (Fig. 3 in the ESM). Protein binding analysis showed no distinct differences between the three treatment groups (Table 4).

\section{Discussion}

Darolutamide has been developed as a tablet for oral administration for the treatment of nonmetastatic CRPC. The absolute bioavailability of darolutamide after a single $300-\mathrm{mg}$ dose as an oral solution under fasted conditions was $~ 100 \%$, indicating complete absorption and high permeability of darolutamide, and that first-pass metabolism does not play a significant role. In contrast, absolute bioavailability of darolutamide administered as a single 300-mg tablet in the fasted state was $\sim 30 \%$. Absorption and bioavailability of the 
Table 4 Plasma pharmacokinetic parameters of single-dose, oral darolutamide $600 \mathrm{mg}$ taken with food in healthy subjects and in patients without cancer with moderate hepatic impairment or severe renal impairment

\begin{tabular}{lrrr}
\hline Parameter & \multicolumn{2}{l}{ Geometric mean/geometric CV\% (range) } \\
\cline { 2 - 4 } & Healthy subjects $(n=10)$ & $\begin{array}{l}\text { Moderate hepatic impairment } \\
(n=9)\end{array}$ & Severe renal impairment $(n=10)$ \\
\hline$C_{\max }, \mu \mathrm{g} / \mathrm{mL}$ & $1.56 / 37.3(0.68-2.37)$ & $2.27 / 38.7(1.30-4.72)$ & $2.47 / 30.7(1.44-3.33)$ \\
$t_{\max }, \mathrm{h}^{\mathrm{a}}$ & $4.00(3.02-12.0)$ & $4.00(4.00-8.00)$ & $4.00(3.00-12.0)$ \\
$\mathrm{AUC}_{0-48}, \mu \mathrm{g} \cdot \mathrm{h} / \mathrm{mL}$ & $21.3 / 41.9(8.25-37.8)$ & $39.4 / 36.5(23.2-67.0)$ & $52.5 / 38.9(28.3-82.3)$ \\
$\mathrm{AUC}_{0-\text { inf }}, \mu \mathrm{g} \cdot \mathrm{h} / \mathrm{mL}$ & $23.3 / 43.4(8.93-42.6)$ & $45.9 / 44.6(24.0-72.9)^{\mathrm{b}}$ & $67.6 / 41.9(31.2-107)^{\mathrm{b}}$ \\
$t_{1 / 2}, \mathrm{~h}$ & $13.6 / 18.2(10.8-20.7)$ & $13.7 / 35.4(9.63-24.6)^{\mathrm{b}}$ & $17.7 / 16.1(13.8-22.8)^{\mathrm{b}}$ \\
Fraction unbound, \% & $7.79 / 8.78(6.49-8.81)$ & $8.79 / 11.1(7.29-10.6)$ & $8.06 / 11.8(6.36-8.95)$ \\
\hline
\end{tabular}

$A U C$ area under the plasma concentration-time curve, $A U C_{0-48} \mathrm{AUC}$ from time 0 to $48 \mathrm{~h}$ after administration, $C_{\max }$ maximum (peak) plasma concentration, $C V \%$ coefficient of variation, $t_{1 / 2}$ elimination half-life, $t_{\max }$ time to peak concentration

${ }^{\mathrm{a}}$ Data are presented as median (range)

${ }^{\mathrm{b}} n=7$

darolutamide tablet were markedly improved to $~ 60-75 \%$ when given with food [9]. The observed increased bioavailability is consistent with in vitro data that show improved solubility in fed vs fasted state simulated intestinal fluid (data on file). Therefore, it is recommended that darolutamide is administered with food [16].

Darolutamide is gradually absorbed after oral tablet dosing with or without food, with a median time to peak concentration of 4-6 h after single dosing of $600 \mathrm{mg}$, supporting previous clinical findings $[1,9,10]$. It is rapidly interconverted between the two diastereomers as measured in plasma, with a $1: 1$ ratio in the administered dose changing to favor $(S, S)$-darolutamide over $(S, R)$-darolutamide regardless of the dosing route or formulation (diastereomer ratios for $(S, R)$-darolutamide and $(S, S)$-darolutamide, respectively, ranged from $1: 3$ to $1: 5)$. In vitro studies in human hepatocytes [6] and clearance and $t_{1 / 2}$ data confirm there is more rapid elimination of $(S, R)$-darolutamide than $(S, S)$-darolutamide from plasma, resulting in the observed preponderance of $(S, S)$-darolutamide following dosing. As $(S, R)$-darolutamide and $(S, S)$-darolutamide exhibit the same physicochemical, pharmacologic, and toxicologic properties, both diastereomers are considered to contribute equally and interchangeably to the efficacy and safety of darolutamide [4, 17].

Plasma concentrations of the major metabolite ketodarolutamide were 1.7-fold higher than for darolutamide after oral tablet administration in healthy subjects; however, the free fraction of keto-darolutamide was $<1 \%$, markedly lower than for darolutamide $(8 \%)$. Hence, based on the similar pharmacologic activity of the parent drug and metabolite observed in vitro [2], pharmacologic activity is considered to be driven by the parent diastereomers, as their free concentrations considerably exceed that of the keto-metabolite. Serum albumin was identified as the main binding protein for parent and metabolite; thus, disease state (as known for alpha-1 acid glycoprotein [18]), steroid hormone levels (as known for steroid hormone-binding globulin [19]), and protein binding saturation are considered unlikely to affect the free fraction of darolutamide.

In healthy subjects, darolutamide exhibited time-independent (no autoinduction) and predictable pharmacokinetics after repeated oral administration at the therapeutic dose of $600 \mathrm{mg}$ BID taken with food. Darolutamide exposure $\left(\mathrm{AUC}_{0-12}\right)$ after multiple dosing was similar to the exposure after a single dose $\left(\mathrm{AUC}_{0-\mathrm{inf}}\right)$. Dose linearity of the pharmacokinetics of darolutamide in the range of 100-700 mg BID was shown in the phase I/II dose-escalation study in patients with metastatic CRPC $[1,17]$. The pharmacokinetic behavior of the diastereomers and keto-darolutamide generally followed the same trends as darolutamide. Accordingly, peak concentration of the diastereomers and keto-darolutamide was reached around the same time, with a median $t_{\max }$ between 4 and $6 \mathrm{~h}$. The terminal $t_{1 / 2}$ was similar for $(S, S)$ darolutamide and keto-darolutamide.

Darolutamide reaches steady state quickly in a clinical setting and has a much shorter half-life than other secondgeneration androgen receptor inhibitors [20, 21]. This pharmacokinetic profile is favorable should dose adaptation be required to manage drug-related safety events.

The phase I study in patients without cancer with renal or hepatic impairment revealed a distinct effect of severe renal impairment and moderate hepatic impairment on the pharmacokinetics of darolutamide (2.5-fold and 1.9-fold exposure increase, respectively). A population pharmacokinetic modeling analysis, conducted in a subset of patients with nonmetastatic CRPC in ARAMIS, indicated that darolutamide exposure was at most only slightly higher in patients with mild or moderate renal impairment and not higher in patients with mild hepatic impairment vs patients with 
normal organ function [22]. As there were only single cases of patients with severe renal and moderate hepatic impairment included in ARAMIS, pharmacokinetic and safety data in this population are very limited. A safety subgroup analysis showed that adverse events were consistent across renal and hepatic function groups and comparable between darolutamide and placebo arms [17, 22]. Although available data on the pharmacokinetics of darolutamide and safety in patients with cancer with severe renal and moderate hepatic impairment are limited, consideration of the risk-benefit balance indicates that a starting dose of $300 \mathrm{mg}$ BID can provide exposure within the range to achieve effective disease control, with the option to escalate to the standard 600mg BID dose if well tolerated [17].

The data presented herein are limited to healthy male subjects and patients without cancer with moderate hepatic or severe renal impairment to allow a detailed description of the pharmacokinetic characteristics of darolutamide. Our information adds to the evidence base on the pharmaco kinetics of darolutamide, which includes previously reported analyses of Caucasian and Japanese patients with metastatic CRPC and patients with nonmetastatic CRPC [9-11, 22, 23]. Overall, patients with cancer (metastatic or nonmetastatic) appear to have greater exposure and a longer effective $t_{1 / 2}$ than healthy subjects (Fig. 4), but there is a large overlap in exposure and the difference in the pharmacokinetic profile of darolutamide between patients with cancer and healthy subjects is small. Reduced organ function due to age or disease, combined with a more frequent use of comedications in patients with cancer than in healthy subjects, may contribute to observed differences.

\section{Conclusions}

Darolutamide exhibits predictable linear pharmacokinetics and rapidly reaches steady state when administered orally at the recommended dose of $600 \mathrm{mg}$ BID. As the $(S, S)$ and $(S, R)$ diastereomers exhibit similar pharmacologic and toxicologic properties, they are likely to contribute equally and interchangeably to the efficacy and safety of darolutamide. There is no impact of mild hepatic or mild or moderate renal impairment on the pharmacokinetics of darolutamide. Moderate hepatic impairment and severe renal impairment increase the exposure of darolutamide, which can be managed with the recommended reduction of the starting dose to $300 \mathrm{mg}$ BID.

An audio summary of the article can be found here. (MP4 $92844 \mathrm{~kb})$
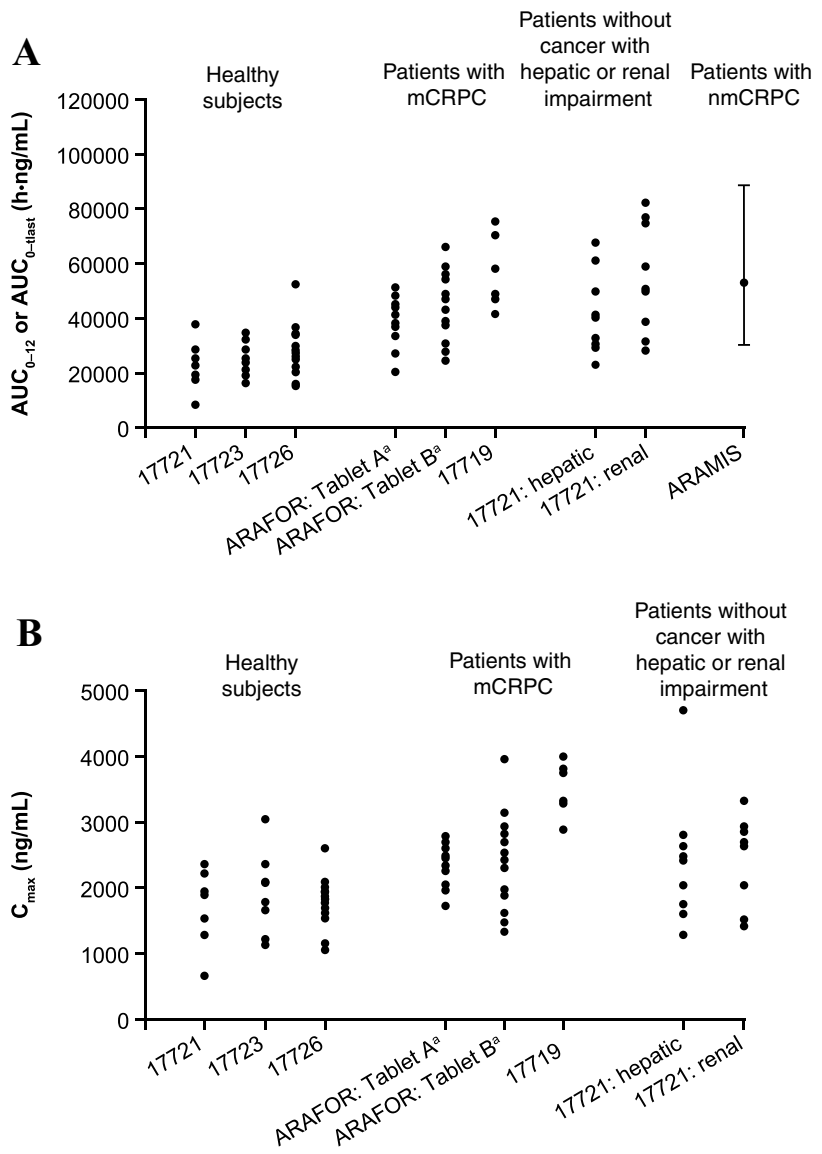

Fig. 4 Comparison of healthy male subjects, patients without cancer with hepatic or renal impairment, and patients with cancer for exposure (a) and maximum (peak) plasma concentration $\left[C_{\max }\right](\mathbf{b})$ after single-dose darolutamide $600 \mathrm{mg}$, and exposure after repeated twice-daily darolutamide $600 \mathrm{mg}$ [7, 9-11]. Area under the concentration-time curve from time 0 to $12 \mathrm{~h}$ after darolutamide administration $\left(\mathrm{AUC}_{0-12}\right)$ at steady state (including the 5 th and 95 th percentiles) is presented for patients with non-metastatic castration-resistant prostate cancer (nmCRPC). Studies 17721, 17726, and ARAFOR evaluated single doses of darolutamide, whereas studies 17723, 17719, and ARAMIS evaluated multiple doses. Study 17726 was a phase I, drugdrug interaction study evaluating the effects of cytochrome P450 3A4 inducers on the pharmacokinetics of darolutamide [11]. ${ }^{\mathrm{a}}$ Tablet $\mathrm{A}$ and Tablet B were the same immediate-release formulation of darolutamide, but a coarser grade of drug substance was used in Tablet B [9]. $A U C_{0-\text { tlast }}$ area under the concentration-time curve from time 0 to the last concentration above the lower limit of quantification, $m C R P C$ metastatic castration-resistant prostate cancer, nmCRPC nonmetastatic castration-resistant prostate cancer

Supplementary Information The online version contains supplementary material available at https://doi.org/10.1007/s40262-021-01078-y.

Acknowledgements The authors thank the participants, their families, and all investigators involved in these studies. Dr. Philip Evans of Quotient Clinical (Nottingham, UK) led the ARIADME study (NCT02418650). Dr. Matthias Berse of Clinical Research Services Berlin GmbH (Berlin, Germany) led Study 17723 (NCT02671097). Dr. Atef Halabi of CRS Clinical Research Services Kiel GmbH, (Kiel, Germany) led Study 17721 (NCT02894385). Timo Korjamo and Robert 
Fricke are acknowledged for performing the protein binding analysis. Hanna Wartiovaara and Richard Abbott are acknowledged for supervision of the bioanalytical work. Arja Vuorela is acknowledged for scientific support in the ARIADME study. Bayer AG Pharmaceuticals and Orion Pharma division were involved in the study design, collection, analysis, and interpretation of data, as well as data checking of information provided in the manuscript. Ultimate responsibility for opinions, conclusions, and data interpretation lies with the authors.

\section{Declarations}

Funding Funding for this work was provided by Bayer AG and Orion Corporation Orion Pharma.

Conflicts of interest/competing interests Susanne Reschke reports employment by Bayer. Christian Zurth, Funan Huang, and Gary Wilkinson report employment by and stock ownership in Bayer. Pirjo Nykänen, Päivi Taavitsainen, and Annamari Vuorela report employment by Orion Pharma. Mikko Koskinen reports employment by and stock ownership in Orion Pharma. Medical writing support, including assisting authors with the development of the outline and initial draft and incorporation of comments, was provided by Francesca Kolbe, $\mathrm{PhD}$, and Tamsin Williamson, and editorial support was provided by Annabel Ola, MSc, all of Scion (London, UK) supported by Bayer Healthcare Pharmaceuticals, Inc. (Whippany, NJ, USA). Medical writing support, including assisting authors with the development of the submission draft, was provided by Sara Black, ISMPP CMPPTM, of OPEN Health Communications (London, UK), supported by Bayer.

Ethics approval All studies were conducted in accordance with the International Council for Harmonization Good Clinical Practice, the principles of the Declaration of Helsinki, and all applicable national regulations. The study protocols were reviewed and approved by the following independent ethics committees: Wales Research Ethics Committee 2, Cardiff, UK (ARIADME Study); Ethik-Kommission der Ärztekammer Schleswig-Holstein, Bad Segeberg, Germany (Study 17721); and Landesamt für Gesundheit und Soziales Geschäftsstelle der Ethik-Kommission des Landes Berlin, Berlin, Germany (Study 17723).

Consent to participate For all clinical studies described in the article, informed consent was obtained from the participants.

Consent for publication All patients provided consent for publication of their pooled, anonymized data.

Availability of data and material Availability of the data underlying this publication will be determined later according to Bayer's commitment to the EFPIA/PhRMA "Principles for responsible clinical trial data sharing". This pertains to the scope, timepoint, and the process of data access. As such, Bayer commits to sharing, upon request from qualified scientific and medical researchers, patient-level clinical trial data, study-level clinical trial data, and protocols from clinical trials in patients for medicines and indications approved in the USA and European Union as necessary for conducting legitimate research. This applies to data on new medicines and indications that have been approved by the European Union and US regulatory agencies on or after 1 January, 2014. Interested researchers can use www.clinicalst udydatarequest.com to request access to anonymized patient-level data and supporting documents from clinical studies to conduct further research that can help advance medical science or improve patient care. Information on the Bayer criteria for listing studies and other relevant information is provided in the study sponsors section of the portal. Data access will be granted to anonymized patient-level data, protocols, and clinical study reports after approval by an independent scientific review panel. Bayer is not involved in the decisions made by the independent review panel. Bayer will take all necessary measures to ensure that patient privacy is safeguarded.

Code availability Not applicable.

Author contributions Participated in clinical study design: PT, PN, MK, AV, and CZ. Conducted experiments: PN, SR, PT, AV, and GW. Performed data analysis: FH, MK, PN, PT, and CZ. Wrote or contributed to the writing of the manuscript: FH, MK, PN, SR, PT, AV, GW, and $\mathrm{CZ}$.

Open Access This article is licensed under a Creative Commons Attribution-NonCommercial 4.0 International License, which permits any non-commercial use, sharing, adaptation, distribution and reproduction in any medium or format, as long as you give appropriate credit to the original author(s) and the source, provide a link to the Creative Commons licence, and indicate if changes were made. The images or other third party material in this article are included in the article's Creative Commons licence, unless indicated otherwise in a credit line to the material. If material is not included in the article's Creative Commons licence and your intended use is not permitted by statutory regulation or exceeds the permitted use, you will need to obtain permission directly from the copyright holder. To view a copy of this licence, visit http://creativecommons.org/licenses/by-nc/4.0/.

\section{References}

1. Fizazi K, Massard C, Bono P, Jones R, Kataja V, James N, et al. Activity and safety of ODM-201 in patients with progressive metastatic castration-resistant prostate cancer (ARADES): an open-label phase 1 dose-escalation and randomised phase 2 dose expansion trial. Lancet Oncol. 2014;15(9):975-85.

2. Moilanen AM, Riikonen R, Oksala R, Ravanti L, Aho E, Wohlfahrt G, et al. Discovery of ODM-201, a new-generation androgen receptor inhibitor targeting resistance mechanisms to androgen signaling-directed prostate cancer therapies. Sci Rep. 2015;5:12007.

3. Fizazi K, Smith MR, Tombal B. Clinical development of darolutamide: a novel androgen receptor antagonist for the treatment of prostate cancer. Clin Genitourin Cancer. 2018;16(5):332-40.

4. Sugawara T, Baumgart SJ, Nevedomskaya E, Reichert K, Steuber $\mathrm{H}$, Lejeune $\mathrm{P}$, et al. Darolutamide is a potent androgen receptor antagonist with strong efficacy in prostate cancer models. Int $\mathbf{J}$ Cancer. 2019;145(5):1382-94.

5. Taavitsainen $\mathrm{P}$, Gieschen H, Korjamo T, Kahkonen M, Malmstrom $\mathrm{C}$, Prien O, et al. Absorption, distribution, metabolism and excretion of darolutamide (a novel non-steroidal androgen receptor antagonist) in rats. Xenobiotica. 2020;50(8):967-79.

6. Taavitsainen P, Prien O, Kähkönen M, Niehues M, Korjamo T, Denner K, et al. Metabolism and mass balance of the novel nonsteroidal androgen receptor inhibitor darolutamide in humans. Drug Metab Dispos. 2021;49(6):420-33.

7. Fizazi K, Shore N, Tammela TL, Ulys A, Vjaters E, Polyakov S, et al. Darolutamide in nonmetastatic, castration-resistant prostate cancer. N Engl J Med. 2019;380(13):1235-46.

8. Fizazi K, Shore N, Tammela TL, Ulys A, Vjaters E, Polyakov $\mathrm{S}$, et al. Nonmetastatic, castration-resistant prostate cancer and survival with darolutamide. N Engl J Med. 2020;383(11):1040-9.

9. Massard C, Penttinen HM, Vjaters E, Bono P, Lietuvietis V, Tammela TL, et al. Pharmacokinetics, antitumor activity, and safety of ODM-201 in patients with chemotherapy-naive metastatic 
castration-resistant prostate cancer: an open-label phase 1 study. Eur Urol. 2016;69(5):834-40.

10. Matsubara N, Mukai H, Hosono A, Onomura M, Sasaki M, Yajima Y, et al. Phase 1 study of darolutamide (ODM-201): a new-generation androgen receptor antagonist, in Japanese patients with metastatic castration-resistant prostate cancer. Cancer Chemother Pharmacol. 2017;80(6):1063-72.

11. Zurth C, Koskinen M, Fricke R, Prien O, Korjamo T, Graudenz $\mathrm{K}$, et al. Drug-drug interaction potential of darolutamide: in vitro and clinical studies. Eur J Drug Metab Pharmacokinet. 2019;44(6):747-59.

12. European Medicines Agency. Guideline on bioanalytical method validation. 2011. https://www.ema.europa.eu/documents/scien tific-guideline/guideline-bioanalytical-method-validation_en.pdf. Accessed 26 Oct 2021.

13. US Food and Drug Administration. Bioanalytical method validation: guidance for industry. 2018. https://www.fda.gov/downloads/ Drugs/Guidances/ucm070107.pdf. Accessed 26 Oct 2021.

14. US Food and Drug Administration. Guidance for industry: pharmacokinetics in patients with impaired hepatic function: study design, data analysis, and impact on dosing and labeling. 2003. https://www.fda.gov/regulatory-information/search-fda-guidancedocuments/pharmacokinetics-patients-impaired-hepatic-functionstudy-design-data-analysis-and-impact-dosing-and. Accessed 26 Oct 2021.

15. Sahin S, Benet LZ. The operational multiple dosing half-life: a key to defining drug accumulation in patients and to designing extended release dosage forms. Pharm Res. 2008;25(12):2869-77.

16. Bayer HealthCare Pharmaceuticals Inc. Nubeqa (darolutamide) US prescribing information. 2019. https://www.accessdata.
fda.gov/drugsatfda_docs/label/2019/212099Orig 1s000lbl.pdf. Accessed 26 Oct 2021.

17. European Medicines Agency. Nubeqa (darolutamide) European public assessment report. 2020. https://www.ema.europa.eu/en/ documents/assessment-report/nubeqa-epar-public-assessmentreport_en.pdf. Accessed 26 Oct 2021.

18. Smith SA, Waters NJ. Pharmacokinetic and pharmacodynamic considerations for drugs binding to alpha-1-acid glycoprotein. Pharm Res. 2018;36(2):30.

19. Hammond GL. Diverse roles for sex hormone-binding globulin in reproduction. Biol Reprod. 2011;85(3):431-41.

20. Gibbons JA, de Vries M, Krauwinkel W, Ohtsu Y, Noukens J, van der Walt JS, et al. Pharmacokinetic drug interaction studies with enzalutamide. Clin Pharmacokinet. 2015;54(10):1057-69.

21. de Vries R, Jacobs F, Mannens G, Snoeys J, Cuyckens F, Chien $\mathrm{C}$, et al. Apalutamide absorption, metabolism, and excretion in healthy men, and enzyme reaction in human hepatocytes. Drug Metab Dispos. 2019;47(5):453-64.

22. US Food and Drug Administration. Multi-discipline review: NUBEQA (darolutamide). 2019. https://www.accessdata.fda.gov/ drugsatfda_docs/nda/2019/212099Orig1s000MultidisciplineR. pdf. Accessed 26 Oct 2021.

23. Shore N, Zurth C, Fricke R, Gieschen H, Graudenz K, Koskinen $\mathrm{M}$, et al. Evaluation of clinically relevant drug-drug interactions with darolutamide in the phase 3 ARAMIS trial for patients with nonmetastatic castration-resistant prostate cancer. Targ Oncol. 2019;14(5):527-39. 